\title{
A Plea to Improve Vaccination and Public Health Strategies Against COVID-19
}

\author{
Frédéric Blavier $^{1,2 *}{ }^{(\mathbb{D}}$, Claire Duflos $^{3}(\mathbb{D}$ \\ ${ }^{1}$ Department of Obstetrics and Gynaecology, Hospital Centre of Arles, Arles, France \\ ${ }^{2}$ Department of Obstetrics and Gynaecology, University Hospital Centre of Montpellier, Montpellier, France \\ ${ }^{3}$ Clinical Research and Epidemiology Unit, University Hospital Centre of Montpellier, Montpellier, France
}

Corresponding Author: Frédéric Blavier, MD, Department of Obstetrics and Gynaecology, Hospital Centre of Arles, Arles, France. Tel: +33-604160774, Email: fredericblavier@yahoo.fr

Received March 6, 2021; Accepted June 1, 2021; Online Published July 26, 2021

Citation: Blavier F, Duflos C. A plea to improve vaccination and public health strategies against covid-19. Int J Travel Med Glob Health. 2021;9(3):146148. doi:10.34172/ijtmgh.2021.24.

\section{Dear Editor,}

The number of doses of vaccine against coronavirus disease (COVID-19) is limited in most countries but some doses are administrated to already immunized asymptomatic people. With serological triages, we could reach an effective collective immunization $^{1}$ swifter and potentially reduce allergic/ immunological reactions (anaphylaxis ${ }^{2}$ ), blood clots, or other uncommon disorders following vaccine(s). Triages should concern all people; anti-spike antibodies could be ignored after asymptomatic COVID-19 but could also be missing after symptomatic COVID-19 (T-cell immunity). ${ }^{3}$ For immunized people (post-infection or/and post-vaccination), persistent immunity could be assessed each 8 months ${ }^{4}$ or more, according to risk(s) of severe COVID-19 and death. ${ }^{5}$ Exceptions could be made, as a vaccine(s) could treat long COVID-19 cases in which anti-Spike antibodies seem insufficient but this hypothesis should be confirmed. Figure 1 illustrates the suggested guidelines for vaccination.

Public measures and their consequences ${ }^{6-10}$ should also be discussed. Lockdowns, or other interventions limiting sport, outdoor activities, schools/universities, cultural and socializing occupations, showed growing medical, psychological, and social damages. They encourage sedentary lifestyles and reduced physical exercise, worsening obesity epidemic and other potential risk factors (diabetes mellitus, hypertension, hyperlipidemia, etc) for severe COVID-19 and death. ${ }^{6}$ Zadow et al quoted "COVID-19, coagulation, and reduced physical activity may contribute to generating a perfect storm, where each fuels the other and potentially increases mortality risk"? Lockdowns, lowering outdoor activities and sun-exposure can promote vitamin $\mathrm{D}$ deficiency, another risk factor for severity and death of COVID19. ${ }^{8}$

Furthermore, lockdowns caused psychological damages to students, ${ }^{9}$ children, adolescents, and adults. Politico-medical communications and decisions intensify psychological and psychiatric disorders such as anxiety, depression, and cyberchondria, ${ }^{10}$ a compulsive search for information on social media creating a vicious cycle which increased with lockdowns and fear. Another vicious circle occurs with excessive media consumption, increasing also anxiety and depression. Students are self-reporting a lower quality of the information received, higher prevalence of suicidal thoughts, severe distress, high level of perceived stress, severe depression, and high level of anxiety during the first French COVID-19 quarantine'; meanwhile, tobacco shops remained open, "for mental health" according to the French government.

Reduction of air pollution (PM10, PM2.5, BC, NOx, SO2, CO, and VOCs, associated with COVID-19 ${ }^{11}$ ) seemed the only positive effect of lockdown, but probably not enough to compensate for all the negative effects. Indeed, a study compared countries interventions and did not find any significant benefit on case growth of more restrictive interventions (such as stay-at-home and business closure). ${ }^{12}$ Another one, studying all countries, states, or regions counting at least ten deaths due to COVID-19 up to August 31, 2020 showed that lockdown or other stringent public measures settled to fight pandemic did not alleviate COVID-19 mortality. ${ }^{13}$ Severe acute respiratory syndrome coronavirus 2 (SARS-CoV-2) can probably spread further among populations concentrated in restricted places at a short time (curfew) than through dispersed free populations.

Finally, people at high risk of severe COVID19 or death,

Copyright $\odot 2021$ The Author(s). This is an open-access article distributed under the terms of the Creative Commons Attribution License (http:// creativecommons.org/licenses/by/4.0), which permits unrestricted use, distribution, and reproduction in any medium, provided the original work is properly cited. 


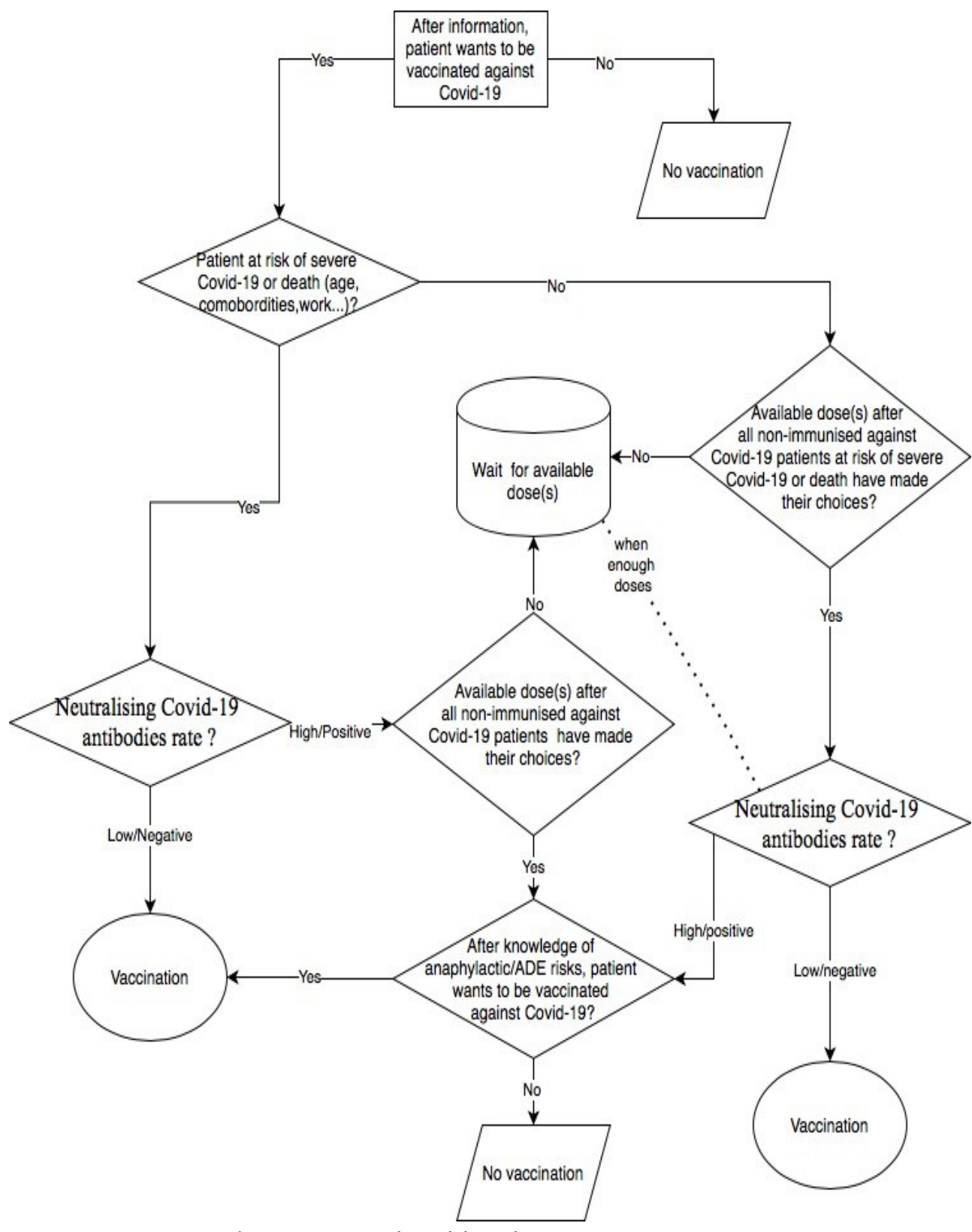

Figure 1. Suggested Guidelines for COVID-19 Vaccination.

indoor, should wear N95/FFP2/NP95 masks more effective than facemasks ${ }^{14}$ or surgical masks and should do outdoor activities, ideally sports, ${ }^{6,7}$ in the sunlight which inactivates rapidly SARS-Cov $2^{15}$ and brings protective effects. ${ }^{8}$ Indoor use of sunlight/UV lamps and wind/ventilation would probably reduce SARS-Cov2 transmissions.

\section{Authors' Contributions}

FB and CD contributed equally to this study.

\section{Conflict of Interest Disclosures}

The authors declare that they have no conflicts of interest.

\section{Ethical Approval}

Not applicable.

\section{Funding/Support}

None.

\section{References}

1. Veldhoen M, Simas JP. Endemic SARS-CoV-2 will maintain post-pandemic immunity. Nat Rev Immunol. 2021;21(3):131132. doi:10.1038/s41577-020-00493-9.

2. Shimabukuro $T$, Nair $N$. Allergic reactions including anaphylaxis after receipt of the first dose of Pfizer-BioNTech COVID-19 vaccine. JAMA. 2021;325(8):780-781. doi:10.1001/ jama.2021.0600.

3. Sekine T, Perez-Potti A, Rivera-Ballesteros O, et al. Robust T cell immunity in convalescent individuals with asymptomatic or mild COVID-19. Cell. 2020;183(1):158-168.e114. doi:10.1016/j. cell.2020.08.017.

4. Dan JM, Mateus J, Kato Y, et al. Immunological memory to SARS-CoV-2 assessed for up to 8 months after infection. Science. 2021;371(6529). doi:10.1126/science.abf4063.

5. Gao YD, Ding $M$, Dong $X$, et al. Risk factors for severe and critically ill COVID-19 patients: a review. Allergy. 2021;76(2):428-455. doi:10.1111/all.14657.

6. Stefan N, Birkenfeld AL, Schulze MB. Global pandemics 
interconnected - obesity, impaired metabolic health and COVID-19. Nat Rev Endocrinol. 2021;17(3):135-149. doi:10.1038/s41574-020-00462-1.

7. Zadow EK, Wundersitz DWT, Hughes DL, et al. Coronavirus (COVID-19), coagulation, and exercise: interactions that may influence health outcomes. Semin Thromb Hemost. 2020;46(7):807-814. doi:10.1055/s-0040-1715094.

8. Whittemore PB. COVID-19 fatalities, latitude, sunlight, and vitamin D. Am J Infect Control. 2020;48(9):1042-1044. doi:10.1016/j.ajic.2020.06.193.

9. Wathelet M, Duhem S, Vaiva G, et al. Factors associated with mental health disorders among university students in France confined during the COVID-19 pandemic. JAMA Netw Open. 2020;3(10):e2025591. doi:10.1001/ jamanetworkopen.2020.25591.

10. Jokic-Begic N, Lauri Korajlija A, Mikac U. Cyberchondria in the age of COVID-19. PLoS One. 2020;15(12):e0243704. doi:10.1371/journal.pone.0243704.
11. Srivastava A. COVID-19 and air pollution and meteorology-an intricate relationship: a review. Chemosphere. 2021;263:128297. doi:10.1016/j.chemosphere.2020.128297.

12. Bendavid E, Oh C, Bhattacharya J, Ioannidis JPA. Assessing mandatory stay-at-home and business closure effects on the spread of COVID-19. Eur J Clin Invest. 2021;51(4):e13484. doi:10.1111/eci.13484.

13. De Larochelambert Q, Marc A, Antero J, Le Bourg E, Toussaint JF. COVID-19 mortality: a matter of vulnerability among nations facing limited margins of adaptation. Front Public Health. 2020;8:604339. doi:10.3389/fpubh.2020.604339.

14. Daoud AK, Hall JK, Petrick H, Strong A, Piggott C. The potential for cloth masks to protect health care clinicians from SARS-CoV-2: a rapid review. Ann Fam Med. 2021;19(1):55-62. doi:10.1370/afm.2640.

15. Ratnesar-Shumate S, Williams G, Green B, et al. Simulated sunlight rapidly inactivates SARS-CoV-2 on surfaces. J Infect Dis. 2020;222(2):214-222. doi:10.1093/infdis/jiaa274. 